\title{
A PARTICIPAÇÃO DA COMUNIDADE EDUCATIVA NA CONSTRUÇÃO DA GESTÃO DEMOCRÁTICA
}

\section{THE PARTICIPATION OF THE EDUCATIONAL COMMUNITY IN BUILDING DEMOCRATIC MANAGEMENT}

\section{Bruna Maravai ${ }^{1}$}

Maria Aparecida da Silva Mello²

RESUMO: A gestão democrático-participativa se constitui a partir dos processos de participação e ações conjuntas entre a equipe gestora e os demais membros da comunidade educativa. Nesse contexto, o trabalho de pesquisa foi realizado no âmbito de três escolas da rede estadual de ensino da cidade de Siderópolis - SC. As abordagens utilizadas na pesquisa são de base qualitativa, exploratória e descritiva através de entrevistas semiestruturadas, com o propósito de responder ao seguinte problema de pesquisa: qual a influência da participação da comunidade educativa na construção de uma gestão democrática? O objetivo geral foi analisar a influência da participação da comunidade educativa na construção da gestão democrática. Nesse contexto, elencaram-se os objetivos específicos: verificar o papel do gestor na construção da gestão democrática; analisar o processo de construção do PPP na escola; identificar o papel do Conselho Escolar na estrutura geral da escola; identificar a existência de órgãos colegiados na escola. Tendo como suporte os objetivos citados, o referencial teórico é constituído por três capítulos, nos quais foram utilizados como bases teóricas para fundamentar o estudo os autores: Ferreira e Souza (2009), Libâneo (2015), Paro (2001), Veiga (2013), Veiga (2002), Antunes e Carvalho (2008) e Galina e Carbello (2008). Após análise dos dados desse processo investigativo, constata-se que, embora haja o reconhecimento da influência da comunidade educativa na construção da gestão democrática, há necessidade de buscar outras formas de ampliar e melhorar o processo de participação da comunidade educativa na escola, principalmente as relacionadas à aprendizagem dos estudantes.

PALAVRAS-CHAVE: Gestão democrático-participativa. Projeto Político Pedagógico. Conselho Escolar.

\footnotetext{
${ }^{1}$ Graduada em Pedagogia da Unesc. bruna_maravai@hotmail.com

${ }^{2}$ Pedagoga. Mestre em Educação.msm@unesc.net
} 


\section{SABERES PEDAGÓGICOS}

Revista do Curso de Graduaçāo de Pedagogia - Unesc

ISSN 2526-4559

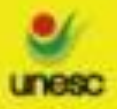

thising

ABSTRACT: The participatory democratic management is constituted of the processes of participation and joint actions between the management team and the other members of the educational community. In this connection, the research work was carried out in three schools of the state school system of the city of Siderópolis - SC. The approaches used in the research are qualitative, exploratory and descriptive based on semi-structured interviews whose purpose was to answer the research problem: what is the influence of the participation of the educational community in the building of a democratic management? The main goal was to analyze the influence of the participation of the educative community in the construction of the democratic management. The following objectives were listed: to verify the role of the manager in the building of the democratic management; to analyze the process of building PPP at school; to identify the role of the School Council in the whole structure of the school; to identify an entity of collegiate bodies in the school. Based on the aforementioned objectives, the theoretical framework consists of three chapters, which were used as theoretical bases to support the study: Ferreira and Souza (2009), Libâneo (2015), Paro (2001), Veiga (2013), Veiga (2002), Antunes and Carvalho (2008) and Galina and Carbello (2008). Then analyzing the data of this investigative process, it appears that, although there is recognition of the influence of the educational community in the building of democratic management, there is a need to look for other ways to expand and improve the process of participation of the educational community in school, especially related to student learning.

KEYWORDS: Participatory Democratic Management. Pedagogical Political Project. School Council.

\section{INTRODUÇÃO}

O presente trabalho de pesquisa surgiu a partir das aulas da sexta fase do curso de graduação em Pedagogia da Universidade do Extremo Sul Catarinense (UNESC), na disciplina de Gestão de Processos Educativos, ministrada pela professora Maria Aparecida da Silva Mello. O propósito desse trabalho surgiu da necessidade de compreender a gestão escolar, na perspectiva da gestão democrático-participativa, e de que maneira a comunidade educativa pode estar inserida nesse contexto, fazendo com que haja unidade de objetivos e ações e, assim, contribuir efetivamente para uma educação de qualidade.

Este estudo pretende abordar aspectos teóricos e práticos sobre a gestão democrática na escola e a importância do Projeto Político Pedagógico e do Conselho Escolar como instâncias de participação. Ao referendar o aspecto democrático nos processos de gestão escolar, destaca-se a relevância da comunidade educativa nos processos de gestão e nas tomadas de decisões de modo a propiciar uma efetiva integração entre escola e comunidade.

Saberes Pedagógicos, Criciúma, v. 4, n², maio/agosto 2020.- Curso de Pedagogia- UNESC 


\section{SABERES PEDAGÓGICOS}

Revista do Curso de Graduaçāo de Pedagogia - Unesc

ISSN 2526-4559

Nessa perspectiva, definiu-se o seguinte problema de pesquisa: qual a influência da participação da comunidade educativa na construção de uma gestão democrática? A discussão sobre os canais de participação e a responsabilidade de conscientizar a comunidade educativa e mobilizá-la para que participe ativamente dos processos educativos são desafios que permeiam a ação gestora, mas que se tornam indispensáveis numa escola que se quer seja democrática.

Em consonância com os aspectos supracitados, definiu-se como objetivo geral: analisar a influência da participação da comunidade educativa na construção da gestão democrática. Nesse contexto, elencaram-se os objetivos específicos: verificar o papel do gestor na construção da gestão democrática; analisar o processo de construção do PPP na escola; identificar o papel do Conselho Escolar na estrutura geral da escola; identificar a existência de órgãos colegiados na escola.

Tendo como suporte os objetivos citados, o referencial teórico é constituído por três capítulos com os seguintes temas: gestão democrática: aspectos históricos e conceituais; Projeto Político Pedagógico; Conselho Escolar e demais órgãos colegiados. Como bases teóricas para fundamentar o estudo foram utilizados os autores: Ferreira e Souza (2009), Libâneo (2015), Paro (2001), Veiga (2013), Veiga (2002), Antunes e Carvalho (2008) e Galina e Carbello (2008).

Em seguida, são apresentados os aportes metodológicos e os resultados das entrevistas, seguidas da conclusão.

\section{GESTÃO DEMOCRÁTICO-PARTICIPATIVA: ASPECTOS HISTÓRICOS E CONCEITUAIS}

O termo gestão vem do "verbo latino gero, gessi, gestum, gerere, [...] na qual o seu "significado é levar sobre si, carregar, chamar para si, executar, exercer e gerar" (FERREIRA; SOUZA, 2009, p.10). A palavra gestão caracteriza um novo olhar para a gerência que promova discussões, conversação e decisões que abracem toda a comunidade educativa (FERREIRA; SOUZA, 2009). Consequentemente, para Antunes e Carvalho (2008, 
p. 20), "a palavra democracia tem sua origem na Grécia Antiga (demo = povo e kracia $=$ governo)".

A gestão democrática teve seu início em algumas escolas municipais e no Estado de Santa Catarina no final da década de 80 e sua instauração deu-se a partir da escolha de diretores por meio de processos eletivos, formação do Conselho Escolar e com a implantação do Projeto Político Pedagógico (ANTUNES; CARVALHO, 2008).

Portanto, Antunes e Carvalho (2008, p. 21) afirmam que "a democratização da escola não é uma via de mão única”. Desse modo, distingue-se do padrão que antes tinha um foco autoritário e centralizador, dando agora espaço para o envolvimento e participação de toda comunidade educativa (ANTUNES; CARVALHO, 2008).

A concepção democrático-participativa prevê a participação ativa de todos os membros da comunidade educativa e tem no gestor o principal articulador, além de detentor de autoridade para a consecução dos objetivos da escola (LIBÂNEO, 2015).

Desse modo, o documento de Lei de Diretrizes e Bases da Educação Nacional menciona na Lei ${ }^{\circ} 9.394$ de 20 de dezembro de 1996 os artigos:

Art. 14. Os sistemas de ensino definirão as normas de gestão democrática do ensino público na educação básica, de acordo com as suas peculiaridades e conforme os seguintes princípios: I - participação dos profissionais da educação na elaboração do projeto pedagógico da escola; II - participação das comunidades escolar e local em conselhos escolares ou equivalentes. Art. 15. Os sistemas de ensino assegurarão às unidades escolares públicas de educação básica que os integram progressivos graus de autonomia pedagógica e administrativa e de gestão financeira, observadas as normas gerais de direito financeiro público (BRASIL,1996).

Assim, um dos aspectos principais para a efetivação da gestão democrática e em atendimento aos preceitos legais, a participação, por meio dos órgãos colegiados, configura a concepção de gestão adotada, de tal modo que pais, estudantes, docentes, funcionários, gestão e comunidade participem ativa e conjuntamente em direção dos objetivos definidos (GALINA; CARBELLO, 2008).

A concepção democrático-participativa trabalha principalmente com a participação, pois permite à inclusão de toda a comunidade educativa em prol de um trabalho 
coletivo, aproximando professores, alunos e pais nas tomadas de decisões com relação aos objetivos, metas, conteúdos, regras, estrutura, entre outros pontos (LIBÂNEO, 2015).

A palavra participação pode fazer referência a duas definições diferentes no ambiente escolar como, por exemplo, por um lado a participação seria o elemento de aquisição da autonomia da instituição, sendo "formativo, pedagógico, metodológico e curricular" (LIBÂNEO, 2015, p. 117), ou então um procedimento institucional, no qual os membros do grupo educacional dividem conhecimentos em prol do ambiente escolar integrado e marcado pela unidade dos propósitos (LIBÂNEO, 2015).

\begin{abstract}
A autonomia é o fundamento da concepção democrático participativa de gestão escolar, razão de ser do projeto pedagógico. Ela é definida como faculdade das pessoas de autogovernar-se, de decidir sobre seu próprio destino. Autonomia de uma instituição significa ter poder de decisão sobre seus objetivos e suas formas de organização manter-se relativamente independente do poder central administrar livremente os recursos financeiros. Assim as escolas podem traçar seu próprio caminho envolvendo professores, alunos, funcionários, pais e comunidade próxima que se tornam corresponsáveis pelo êxito da instituição (LIBÂNEO, 2015, p. 118).
\end{abstract}

Todo esse processo se dá pela autonomia, por meio de ações independentes do poder central e interações conjuntas entre gestão e comunidade educativa. $O$ fato de a instituição poder definir o caminho a seguir, através de objetivos e propósitos construídos coletivamente, confere a possibilidade de gerir administrativa, pedagógica e financeira seus recursos e processos educativos (LIBÂNEO, 2015).

O ambiente escolar é um espaço aberto que favorece as interações além da correlação entre recursos e organização do trabalho na unidade escolar (LIBÂNEO, 2015). Já a relação orgânica entre a direção e a participação dos membros da equipe escolar ocorre por meio da responsabilidade e do envolvimento de todos como um compromisso particular individual de toda comunidade educativa, pois é com a liderança do gestor que todos os membros elaboram o projeto pedagógico curricular que ocorre por meio de discussões coletivas entre todos os envolvidos (LIBÂNEO, 2015).

Desse modo, na ação organizacional o diretor:

[...] coordena, mobiliza, motiva, lidera, delega as responsabilidades decorrentes das decisões aos membros da equipe escolar conforme suas atribuições específicas,

Saberes Pedagógicos, Criciúma, v. 4, n², maio/agosto 2020.- Curso de Pedagogia- UNESC 
presta conta e submete à avaliação da equipe o desenvolvimento das decisões tomadas coletivas (LIBÂNEO, 2015, p. 119).

O envolvimento da comunidade educativa no ambiente escolar apresenta um relacionamento uníssono entre os membros da equipe escolar, pois ao atuar nos órgãos colegiados da escola, como conselhos, Associação de Pais e Mestres (APP), Conselho Escolar ou deliberativo, entre outros, passam a contribuir com o desenvolvimento da escola e favorecer o processo democrático na tomada de decisões (LIBÂNEO, 2015).

Tais premissas permitem romper com práticas desarticuladas e individualistas para dar vazão aos processos participativos, dialógicos, interativos e cooperativos, contribuindo assim, para melhores resultados de aprendizagem (LIBÂNEO, 2008).

Assim, a escola não pode ser vista como uma organização isolada e descontextualizada dos processos sociais, mas voltada a um contexto dinâmico e integrado, mobilizadas por processos democrático-participativos, onde todos trabalham juntos de modo colaborativo, com objetivos comuns.

Nessa perspectiva, outra maneira de consolidar os procedimentos democráticos na escola, trata-se da escolha dos dirigentes escolares. De acordo com Libâneo (2005), é importante que os candidatos a diretor da escola devam possuir uma formação técnica, didático-pedagógica e um perfil de liderança que o ajude a ter um bom desempenho em sua função gestora.

Para dar sustentação a questão em pauta, entende-se que o gestor escolar deve ser eleito pelo voto da comunidade educativa, pois, como afirma Paro (2001, p. 25), "não pode haver democracia plena sem pessoas democráticas para exercê-la”. Assim, a eleição do diretor é uma das principais práticas de democracia, dentro do ambiente escolar (PARO, 2001).

Tais práticas ficam evidenciadas quando o Estado de Santa Catarina determina que para participar como candidato as eleições de diretor da escola, o professor deve apresentar um plano de gestão e seguir uma sequência de requisitos para ocupar a função gratificada (SANTA CATARINA, 2015).

Nesse sentido, há que se dar destaque a participação dos pais no acompanhamento das atividades escolares do filho, de modo a incentivar e ajudá-lo a reconhecer o prazer de aprender e a importância dos estudos para a vida. Além disso, acredita-se que esse

Saberes Pedagógicos, Criciúma, v. 4, n², maio/agosto 2020.- Curso de Pedagogia- UNESC 
acompanhamento constante e permanente favorecerá a melhoria do desempenho da criança no seu processo de aprendizagem (LOPES s/d).

Assim, em consonância com tais prerrogativas, entende-se que o processo de gestão democrático-participativa possui várias faces, que atribui aos partícipes do processo educativo a oportunidade de contribuir com sua efetiva participação nos rumos ou caminhos a serem seguidos, além de ajudar a cumprir com êxito a função social da escola, qual seja, garantir a aprendizagem dos sujeitos e a formação do cidadão.

\section{PROJETO POLÍTICO PEDAGógICO}

Um dos pontos principais de atuação democrática dentro do ambiente escolar é a elaboração do Projeto Político Pedagógico como um documento constituído e planejado por todos os membros da comunidade educativa, em que estarão descritas as finalidades, as diretrizes, ações que orientarão todo processo educativo na unidade escolar, tais como: “procedimentos, instrumentos, modos de agir, estruturas, hábitos e valores." (LIBÂNEO, 2015, p. 127).

Portanto, Veiga (2002) demonstra que o projeto procura um caminho a ser seguido decorrente do envolvimento de todos os membros que compõem a comunidade educativa. Possui um caráter político, preconiza a responsabilidade com a formação do cidadão consciente e crítico e que seja capaz de transformar a sociedade por meio de suas intervenções. Ao falar do caráter pedagógico, entende-se que deve revelar uma intenção, no sentido de responder aos anseios e necessidades daquela comunidade educativa (VEIGA, 2002).

Veiga (2002, p. 1) afirma que:

[...] o projeto político-pedagógico vai além de simples agrupamentos de planos de ensino e de atividades diversas. O projeto não é algo que é construído e em seguida arquivado ou encaminhado às autoridades educacionais como prova do cumprimento de tarefas burocráticas. Ele é construído e vivenciado em todos os momentos, por todos os envolvidos com o processo educativo da escola. 


\section{SABERES PEDAGÓGICOS}

Revista do Curso de Graduaçāo de Pedagogia - Unesc

ISSN $2526-4559$

Nesse sentido o projeto político-pedagógico cumpre o papel de constituir-se em um instrumento de gestão democrática desde sua elaboração e execução e vivenciado, além de acompanhado e avaliado constantemente. A gestão democrática trabalha com o envolvimento de todos nas tomadas de decisões e atos que dizem respeito ao ambiente escolar. Assim, Veiga (2013, p. 18) afirma que “[...] fica claro entender que a gestão democrática, no interior da escola, não é um princípio fácil de ser consolidado, pois trata-se da participação crítica na construção do Projeto Político Pedagógico e na sua gestão” (VEIGA, 2013).

Consequentemente, para a elaboração do Projeto Político Pedagógico, Veiga (2013) apresenta que deve haver no mínimo sete informações que são consideradas fundamentais na constituição do documento, quais sejam: "as finalidades da escola; estrutura organizacional; o currículo; tempo escolar; o processo de decisão; as relações de trabalho; a avaliação" (VEIGA, 2013, p. 22). Ao abordar sobre a finalidade da escola, a autora apresenta a questão do que é desejado, o que é necessário planejar para atingir os objetivos almejados.

Quanto à estrutura organizacional, Veiga (2013) destaca duas classes de mecanismos fundamentais: a estrutura administrativa que se articula em "recursos humanos, físicos e financeiros" (VEIGA, 2013, p. 24) e também se baseia na parte material da escola, como: "arquitetura, equipamentos, mobiliário, cores, limpeza e saneamento básico" (VEIGA, 2013, p. 25) e na estrutura pedagógica voltando seu olhar para as questões de influência nos assuntos de "política, ensino-aprendizagem e currículo" (VEIGA, 2013, p. 25).

O currículo escolar é de fundamental valor, pois é indispensável dentro da organização da escola. Veiga (2013, p. 26) cita que o "currículo é uma construção social do conhecimento [...]”. Assim, para sua elaboração é necessário analisar quatro pontos essenciais. $\mathrm{O}$ primeiro ponto mostra que o currículo não deve ser um documento igualitário. Já no segundo ponto "o currículo não pode ser separado do contexto social, uma vez que ele é historicamente situado e culturalmente determinado" (VEIGA, 2013, p. 27). No terceiro ponto considera o modelo de organização curricular que será seguido pelo ambiente escolar. E no último e quarto ponto "refere-se à questão do controle social, já que o currículo formal (conteúdos curriculares, metodologia e recursos de ensino, avaliação e relação pedagógica) implica controle." (VEIGA, 2013, p. 28). 
No tempo escolar Veiga (2013) aborda a importância e função do tempo dentro do ambiente escolar, pois é ele que irá organizar o calendário letivo, o qual contém os feriados, férias, eventos escolares, entre outros, e também determina o horário escolar, sendo assim o número de horas a ser estudado por dia, por semana, entre outros aspectos (VEIGA, 2013).

Quanto ao processo de decisão, Veiga (2013, p. 31) afirma que:

Isto requer uma revisão das atribuições específicas e gerais, bem como da distribuição do poder e da descentralização do processo de decisão. Para que isso seja possível há necessidade de se instalarem mecanismos institucionais visando à participação política de todos os envolvidos com o processo educativo da escola.

De acordo com a citação acima, entende-se que para assumir uma gestão democrática, cujo processo e descentralização e de compartilhamento na tomada de decisão comprometem seus membros com a instituição de modo a torná-la viável do ponto de vista da governabilidade, requerem-se critérios e conhecimento acerca das atribuições de seus membros de acordo com suas funções (VEIGA, 2013). Na relação de trabalho Veiga (2013) aborda que essa união entre os indivíduos dentro do local do serviço deve ser estabelecida, na qual cada membro precisa desenvolver atos solidários, harmônicos e comunicativos com todo o grupo de trabalho.

Todos os elementos citados que referenciam o Projeto Político Pedagógico como instrumento da gestão democrática visam promover discussões coletivas e organização de ações que venham ao encontro dos objetivos da instituição. Também requerem das pessoas envolvimento, compromisso e clareza a respeito do perfil de sociedade, de escola e de homem que se deseja ajudar a construir. O PPP nessa perspectiva assume um papel agregador ao reunir a comunidade educativa para pensar junto onde se está e aonde se quer chegar.

\section{CONSELHO ESCOLAR E DEMAIS ÓRGÃOS COLEGIADOS}

Para Galina e Carbello (2008), para compreender a efetivação da gestão democrática participativa é necessário citar os instrumentos colegiados que certificam e dão suporte à democracia dentro no ambiente escolar. O Conselho Escolar é a principal instância colegiada na construção da gestão escolar, pois é “o órgão máximo de direção e seus

Saberes Pedagógicos, Criciúma, v. 4, n², maio/agosto 2020.- Curso de Pedagogia- UNESC 
membros devem ter interesses comuns para lutarem juntos com as demais instâncias escolares para promover uma escola de qualidade.” (GALINA; CARBELLO, 2008, p. 28).

A Secretaria de Estado da Educação de Santa Catarina no documento Diretrizes para o Conselho Deliberativo Escolar traz o Art. $2^{\circ}$ da Portaria N/33/15 de 27/08/15, do Conselho Deliberativo escolar nas unidades de educação básica da rede pública estadual, que estabelece as funções:

I - Consultivo - A emissão de pareceres para dirimir dúvidas sobre situações decorrentes das ações pedagógicas, administrativas e financeiras, bem como a proposição de alternativas de soluções e de procedimentos para a melhoria do trabalho escolar. II - Normativo - A elaboração, aprovação e execução do Regimento Interno do Conselho Deliberativo Escolar e participação na elaboração e acompanhamento do Projeto Político-Pedagógico, bem como a aprovação nos casos em que esta não se der por assembleia da comunidade escolar. III - Deliberativo - A tomada de decisões quanto às ações desenvolvidas na Unidade Escolar, respeitando o Projeto Político-Pedagógico da escola, o Plano de Gestão Escolar, as normas legais e as diretrizes administrativas e pedagógicas da Secretaria de Estado da Educação. IV - Avaliativo - A participação na organização e acompanhamento do processo avaliativo da Unidade Escolar nos seus aspectos pedagógicos, administrativos e financeiros. (SANTA CATARINA, 2018, p. 16).

O Conselho Escolar possui um papel de "natureza consultiva, deliberativa, avaliativa e fiscalizadora" (GALINA; CARBELLO, 2008, p. 29), na qual assume a função de acompanhar as atuações "pedagógicas, administrativas, financeiras e políticas públicas desenvolvidas no âmbito escolar." (GALINA; CARBELLO, 2008, p. 29). O Conselho deve desempenhar-se em analisar as atuações educacionais, observando os pontos positivos e negativos e interferindo quando necessário para que se desenvolvam possibilidades para melhor execução. Outro aspecto a ser analisando e observado são os atos da escola, para assim avalizar sua autenticidade (GALINA; CARBELLO, 2008).

O processo de democratização da gestão no ambiente escolar é algo discutido há muitos anos. E foi nos anos 80 na reunião do Fórum de Educação e também no Congresso Mineiro de Educação promovidos pelo estado de São Paulo e de Minas Gerais que se iniciou a abordagem sobre a emancipação do ambiente escolar, dando ao Conselho mais legitimidade. Desse modo, no ano de 1983 passou a existir em determinadas regiões do Brasil a efetivação do Conselho Escolar. Em decorrência dessa nova posição as escolas que já procuravam 
maneiras de integração tinham agora um órgão que vinha ao encontro as suas pretensões de envolvimento com o ambiente escolar (GALINA; CARBELLO, 2008).

O Conselho Escolar segundo a autora tem três funções: deliberativa, consultiva e avaliativa, as quais são bem acentuadas.

\begin{abstract}
A função deliberativa refere-se à tomada de decisões quanto ao direcionamento das ações pedagógicas, administrativas e de gerenciamento dos recursos públicos. A função consultiva refere-se à emissão de pareceres dirimindo dúvidas e propondo soluções para situações no âmbito de sua competência. A função avaliativa refere-se ao acompanhamento sistemático das ações desenvolvidas pela unidade escolar, com o objetivo de identificar problemas e propor alternativas para a melhoria do desempenho em todas as instâncias da vida escolar. (GALINA; CARBELLO, 2008, p. 31).
\end{abstract}

Segundo a Secretaria de Estado da Educação de Santa Catarina, no documento Diretrizes para o Conselho Deliberativo Escolar, art. $3^{\circ}$ do Decreto 3.429/98, compete ao Conselho Deliberativo Escolares as atribuições:

I - Deliberar sobre as diretrizes e metas do Plano Político-Pedagógico da Escola, seus mecanismos de elaboração, aprovação, supervisão e avaliação, que envolvem ações pedagógicas, administrativas e financeiras da Unidade Escolar; II - Propor alternativas de solução, prioridades e procedimentos para melhoria da qualidade do trabalho escolar, respeitando as normas legais vigentes; III - Coordenar e supervisionar com a Direção da Unidade Escolar, a elaboração do Regimento Escolar, calendário letivo, o cumprimento dos dias de efetivo trabalho escolar e horas-aula, estabelecidos na respectiva grade curricular; IV - Apreciar e emitir parecer sobre os relatórios anuais da escola, analisando o seu desempenho em face das diretrizes e metas estabelecidas no Plano Político-Pedagógico; V - Articular-se com outros Conselhos Escolares, criando mecanismos de acompanhamento e execução das políticas educacionais e planos de desenvolvimento da escola; VI Recorrer às instâncias superiores sobre questões que não se julgar apto a decidir e não previstas na legislação e no Regimento Escolar; VII - Elaborar o seu Regimento Interno de acordo com a legislação e normas vigentes. (SANTA CATARINA, 2018, p. 20).

Portanto, está claro que o Conselho Escolar é um dos essenciais organismos democráticos dentro do ambiente escolar (GALINA; CARBELLO, 2008). Outros órgãos colegiados dentro do ambiente escolar são o grêmio estudantil e associação de pais, mestres e funcionários.

O Grêmio Estudantil, segundo Galina e Carbello (2008), é uma constituição democrática, formada por alunos. Não visa lucro, deve conhecer os direitos, deveres e ser a Saberes Pedagógicos, Criciúma, v. 4, n² 2, maio/agosto 2020.- Curso de Pedagogia- UNESC 
voz ativa dos alunos dentro do ambiente escolar. O Grêmio, além disso, tem abertura dentro da escola para desenvolver "atividades educacionais, culturais, cívicas, desportivas e sociais. Também é função do Grêmio realizar intercâmbio de caráter cultural e educacional com outras instituições.” (GALINA; CARBELLO, 2008, p. 33).

A Associação de Pais, Mestres e Funcionários ou também APP, para a autora (2008), é um órgão democrático formado por pais, docentes e funcionários, que não recebem gratificação. Nos dias atuais suas atividades vão ao encontro do Conselho Escolar, que "é atuar na gestão da unidade escolar, participar das decisões relativas à organização e funcionamento da instituição nos aspectos administrativos, pedagógicos e financeiros." (GALINA; CARBELLO, 2008, p. 36).

Em correspondência com os aportes teóricos deste estudo, entende-se que o Conselho Escolar e outros órgãos colegiados presentes na escola constituem-se em instâncias representativas da gestão democrática por meio do processo de autonomia que confere à escola a autoridade de discutir, planejar, implantar e avaliar conjuntamente suas ações e seus propósitos. Isso posto, torna-se um desafio à equipe diretiva da escola incentivar e mobilizar a criação, permanência, fortalecimento e consolidação dos canais de participação nas unidades escolares.

\section{APORTES METODOLÓGICOS E ANÁLISE DE DADOS}

A pesquisa tem como objeto de estudo analisar a influência da participação da comunidade educativa na construção da gestão democrática na visão de três gestores da rede pública estadual da cidade de Siderópolis - SC. Este estudo está fundamentado nos referenciais teóricos disponíveis e na utilização de procedimentos, técnicas e outros artifícios científicos. Com base nas afirmações de Gil (2002, p. 17), a pesquisa pode ser definida como:

[...] o procedimento racional e sistemático que tem como objetivo proporcionar respostas aos problemas que são propostos. A pesquisa é requerida quando não se dispõe de informação suficiente para responder ao problema ou então quando a informação disponível se encontra em tal estado de desordem que não possa ser adequadamente relacionada ao problema. 


\section{SABERES PEDAGÓGICOS}

Revista do Curso de Graduaçāo de Pedagogia - Unesc

ISSN 2526-4559

Na realidade, a pesquisa científica amplia-se durante toda sua produção, pois passa por várias fases, desde a formulação do problema até conseguir alcançar os resultados. Esta pesquisa tem natureza básica com um caráter qualitativo, pois seu desenvolvimento será impulsionado pelas experiências e relatos dos gestores investigados, por meio do processo interativo do pesquisador com a problemática pesquisada. O objetivo que norteará a elaboração do presente trabalho é exploratória e descritiva, pois permite ao pesquisador aproximação com o problema para uma maior compreensão dos fatos e fenômenos a serem pesquisados (GIL, 2002).

\footnotetext{
Assim, o pesquisador planeja um estudo exploratório para encontrar elementos necessários que lhe permitam em contato com determinada população obter resultados que deseja. Um estudo exploratório por outro lado pode servir para levantar possíveis problemas de pesquisa. Visa proporcionar maior familiaridade com o problema com vistas a torná-lo explícito ou a construir hipóteses (PINHEIRO, 2010, p. 21).
}

Nessa perspectiva, o procedimento a ser utilizado na pesquisa é de campo, tendo como sujeitos 3 (três) gestores de escolas da rede estadual da cidade de Siderópolis, e foi executado por meio de entrevistas semiestruturadas, com perguntas básicas fundamentadas em referenciais teóricos relacionados ao tema proposto (TRIVIÑOS, 1987).

$\mathrm{O}$ tema da pesquisa foi apresentado aos pesquisados, que assinaram o termo de consentimento de participação na pesquisa. Por questão de ética, os nomes dos entrevistados e das escolas ficarão em sigilo, sendo os gestores identificados como G1, G2 e G3. Na sequência foram estruturadas categorias de análise como: perfil acadêmico e profissional; gestão democrático-participativa; Projeto Político Pedagógico; Conselho Escolar e demais órgãos colegiados.

Ao abordar a formação acadêmica e profissional, G1 relatou que sua formação é em Educação Física na Unesc e Geografia na Uniasselvi, com pós-graduação Lato Sensu em gestão escolar. A entrevistada G2 possui habilitação em Supervisão escolar e tem vários outros cursos de extensão na área. Já a entrevistada G3 é formada em Ciências com habilitação em Matemática e alegou que não completou a pós-graduação em gestão, entretanto concluiu um curso de 200 horas em gestão escolar oferecido pela Gerência de Educação local.

Saberes Pedagógicos, Criciúma, v. 4, n², maio/agosto 2020.- Curso de Pedagogia- UNESC 
De acordo com os dados coletados sobre a formação acadêmica e experiência profissional, os três entrevistados possuem uma graduação na área da educação e cursos de aperfeiçoamento na gestão escolar, demonstrando assim estarem habilitadas para o exercício da atividade gestora.

Nesse contexto, convém ressaltar, segundo Libâneo (2005, p. 332), “[...] é desejável que os candidatos à eleição ao cargo de gestor tenham formação profissional específica e competência técnica, incluindo liderança, capacidade de gestão e conhecimento de questões pedagógico-didáticas".

No que diz respeito ao papel do gestor na construção da gestão democrática, G1 respondeu que todos os segmentos devem ser ouvidos, sendo eles: a APP (Associação de Pais e Professores), Conselho Deliberativo, professores, alunos, pais e funcionários. A entrevistada G2 afirmou que o gestor é aquele que vai fazer articulações dentro do ambiente escolar, sendo assim seu papel é fundamental no sentido de promover o diálogo constante e a articulação entre os partícipes do processo. “[...] é um papel de diálogo, um papel de conversa e de conseguir enxergar um todo de uma escola para poder trazer a comunidade. Então o papel do gestor nesse sentido é fundamental para que faça toda essa ligação [...].”

A entrevistada G3 expressou que seu papel na construção da gestão é de atuar com uma comunidade participativa, na qual tem como responsabilidade trabalhar uma gestão escolar que envolva toda a comunidade educativa. De acordo com as questões analisadas, pode-se perceber o entendimento dos pesquisados sobre a gestão democrático-participativa, no sentido de promover a participação efetiva da comunidade educativa, através dos órgãos colegiados, nas ações da escola no cumprimento dos objetivos institucionais.

Segundo Libâneo (2008, p. 103)

Uma equipe é um grupo de pessoas que trabalha junto, de forma colaborativa e solidária, visando a formação e a aprendizagem dos alunos. Do ponto de vista organizacional, é uma modalidade de gestão que, por meio da distribuição de responsabilidades, da cooperação, do diálogo, do compartilhamento de atitudes e modos de agir, favorece a convivência, possibilita encarar as mudanças necessárias, rompe com as práticas individualistas e leva a produzir melhores resultados de aprendizagem dos alunos. 
Ainda nessa linha de pensamento, os gestores entrevistados foram indagados sobre o processo de autonomia administrativa, pedagógica e financeira na escola. G1 alegou que trabalha em conjunto com os órgãos colegiados, como conselho deliberativo, APP, grêmio estudantil com objetivo de analisar os gastos, PDDE (Programa Dinheiro Direto na Escola), investimentos, censo e distribuição da merenda. G2 afirmou que a escola possui vários programas no estado, como FNDE (Fundo Nacional de Desenvolvimento da Educação), e que todas as questões relacionadas passam pela APP, sendo que:

[...] a gente discute as prioridades e registra em ata o que vamos fazer com a verba recebida, quais as necessidades, emergência ou as prioridades que temos, então é discutido com os professores, pais e alunos em reunião e é feito uma ata e decidido como vamos fazer, tudo de acordo com a necessidade da escola. (GESTORA 2, 2019).

Ela ainda relatou que em sua escola é tudo delegado, cada um tem sua função, como exemplos os responsáveis pela AEE (Atendimento Educacional Especializado), a secretaria, a ATP (Assistente técnico pedagógico), os professores, a APP e o conselho deliberativo. Citou também que não trabalha centralizado, pois não é uma postura democrática, mas que o gestor tem que saber de tudo. G2 também relatou que:

[...] a APP é mais voltada para a prestação de contas dos serventes, voltando-se mais para a parte financeira, e o conselho deliberativo escolar fica mais na parte de deliberar em tudo com relação à instituição, pois ele vem para ajudar nas tomadas de decisões com relação a problemas com alunos e professores. Com um tempo vai ficar mais o conselho deliberativo escolar, pois entrou com mais força até por que futuramente pelo que a gente sabe, eles vão terceirizar também as serventes e hoje a função de a APP é mais essa parte de banco de pagamento. (GESTORA 2, 2019).

G3 afirmou que trabalha com planejamento de gestão dentro de dimensões, metas e ações.

[...] então é feito uma reunião na semana pedagógica na qual se discute e se traça as dimensões, metas e ações. Logo após é feito reunião com o conselho deliberativo e são passadas todas essas informações. Todas essas dimensões metas e ações são colocadas no PPP. O PPP é nossa bíblia, nosso instrumento de trabalho durante o ano todo, além do regimento escolar que também é utilizado na escola, na qual do mesmo modo ficam registradas todas essas informações. (GESTORA 3, 2019). 


\section{SABERES PEDAGÓGICOS}

Revista do Curso de Graduaçāo de Pedagogia - Unesc

ISSN $2526-4559$

G3 também traz que com relação ao financeiro, a escola recebe recurso da sede, estado e do governo federal. Também recebe propostas de projetos e programas, mas deixa claro que tem autonomia para dizer sim ou não para esses programas. A escola possui neste ano dois programas, o Mais Alfabetização e o PENOA (Programa Estadual Novas Oportunidades de Aprendizagem), sendo que a escola já trabalha o PENOA há cinco anos, no contraturno do aluno.

Assim, com relação a como ocorre o processo de autonomia administrativa, pedagógica e financeira na escola os três gestores trazem a participação dos órgãos colegiados e da comunidade educativa em geral para as tomadas de decisões e são realizadas reuniões coletivas para discutir os pontos importantes e assim colaborar na tomada de decisões.

A concepção democrático-participativa se fundamenta na autonomia da gestão escolar para que a escola tome suas decisões sobre sua forma de organização e seus propósitos institucionais. Esse ato de independência também para gerir os recursos financeiros e trabalhar em conjunto com a comunidade educativa (professores, alunos, pais e funcionários) corrobora para o sucesso da unidade escolar (LIBÂNEO, 2015).

Com relação ao processo de escolha para diretor escolar, G1 ressaltou que a eleição é direta, na qual participam os pais com as matrículas devidamente em dia, alunos do $6^{\circ}$ ano do fundamental II ao $3^{\circ}$ ano do ensino médio, funcionários e professores têm direito ao voto. Essa eleição ocorre de quatro em quatro anos. G2 afirmou que o candidato que queira se escrever tem que postar o plano, que qual passa por uma comissão avaliadora, sendo aprovado pela comissão deve ser apresentado para toda comunidade educativa e somente depois dessas fases é que ocorre a eleição.

G3 respondeu que para se candidatar precisa ser professor efetivo e não pode ter mais que cinco faltas injustificadas. O interessado deve postar o plano de gestão que será avaliado pelo setor competente. Caso seja aprovado, após avaliação, o candidato poderá concorrer à eleição. Segundo a gestora, no estado de Santa Catarina é necessário conter $50+1$ de votos para ser eleito diretor.

Vale ressaltar que o Decreto $\mathrm{N}^{\mathrm{o}} 243$, de $1^{\circ}$ de julho de 2015 , determina em seu Art. $9^{\circ}$ que para elaborar o plano de gestão e participar das eleições para diretor da escola os candidatos devem:

Saberes Pedagógicos, Criciúma, v. 4, n², maio/agosto 2020.- Curso de Pedagogia- UNESC 
Art. $9^{\circ}$ Os profissionais da educação interessados em elaborar Plano de Gestão Escolar, observado o disposto no art. $5^{\circ}$ deste Decreto, com vistas a ocupar a Função Gratificada (FG) de Diretor de Escola, deverão preencher os seguintes requisitos, de acordo com edital próprio elaborado pela SED: I - ser professor, especialista em assuntos educacionais ou assistente técnico-pedagógico, efetivo do Quadro do Magistério Público estadual; II - optar expressamente pelo regime de dedicação exclusiva, a ser ratificado no Termo de Compromisso de Gestão de que trata o $\S 2^{\circ}$ do art. 11 deste Decreto, para ocupar a FG de Diretor de Escola; VI - dispor de carga horária de 40 (quarenta) horas semanais de dedicação à escola; VII comprovar a conclusão ou a matrícula em curso de formação continuada em gestão escolar de no mínimo 200 (duzentas) horas realizado pela SED ou em curso de pósgraduação lato sensu ofertado por instituição de ensino superior credenciada pelo Conselho Estadual de Educação (CEE) ou pelo Ministério da Educação (MEC); VIII - não possuir faltas injustificadas nos 5 (cinco) anos anteriores; IX - não ter sido destituído da função de diretor; e X - ter concluído o transcurso de 12 (doze) meses a partir da remoção. (SANTA CATARINA, 2015, p. 1).

Assim, constata-se que os gestores pesquisados foram eleitos pelo voto direto de toda a comunidade educativa e possuem um plano de gestão aprovado, dando cumprimento aos dispositivos legais e normativos. Ao serem questionadas sobre a elaboração e avaliação do Projeto Político Pedagógico, G1 alegou que o Projeto Político Pedagógico já vem pronto do estado e na escola eles somente organizam conforme os acontecimentos e se ocorreu alguma mudança em lei ou criação de uma nova. Relatou que em todo começo de ano letivo, mas principalmente no mês de março, acontece a reunião com os pais e vai para votação. $\mathrm{O}$ PPP é avaliação no início do ano na reunião pedagógica e na metade do ano também se repete esta avaliação.

A entrevistada G2 afirmou que o Projeto Político Pedagógico também vem prémontado "[...] como é que se diz um corpo, uma espinhazinha, uma espinha dorsal do projeto [...]". Esse projeto é debatido no mês de fevereiro na semana pedagógica com os professores, na qual é observado o que foi feito o que não foi feito no ano. Ela afirmou:

[...] o PPP é avaliado geralmente no mês de fevereiro na semana pedagógica, na qual já se discute o ano que passou e o ano que se inicia. Também fazemos um levantamento dos alunos evadidos, alunos reprovados e aprovados para que se possa fazer uma comparação dos últimos três anos para que assim se consiga realizar uma boa avaliação do que está sendo trabalhado positivamente ou negativamente dentro do PPP. (GESTORA 2, 2019).

A entrevistada G3 relatou que o Projeto Político Pedagógico (PPP) da escola tem uma pré-elaboração feita pela Secretaria de Estado de Educação - SED, com os principais Saberes Pedagógicos, Criciúma, v. 4, n², maio/agosto 2020.- Curso de Pedagogia- UNESC 
pontos, mas caso tenha algo fora da realidade da escola pode-se retirar. A gestora relatou que este ano a escola já está inserindo a Base Nacional Comum Curricular - BNCC no PPP. Quanto à avaliação do PPP, ocorre na semana pedagógica, na qual se exclui ou inclui dados tanto no PPP ou no Regimento Escolar.

Assim, após os relatos pode-se identificar que nas três escolas ocorre uma préelaboração do PPP pelo estado, na qual cada escola irá colocar somente alguns aspectos mais específicos, este assunto é discutido em reunião em que todos fazem a avaliação do PPP, principalmente no início do ano letivo, para que assim se consigam identificar as questões que foram atendidas e o que precisará ser modificado,

Segundo Veiga (2002),

[...] o projeto político-pedagógico vai além de simples agrupamentos de planos de ensino e de atividades diversas. O projeto não é algo que é construído e em seguida arquivado ou encaminhado às autoridades educacionais como prova do cumprimento de tarefas burocráticas. Ele é construído e vivenciado em todos os momentos, por todos os envolvidos com o processo educativo da escola. (VEIGA, 2002, p. 1).

Com base nos aspectos supracitados, percebe-se que o PPP nas escolas pesquisadas não atende na totalidade aos referenciais que defendem a elaboração do documento, pois necessita ser construído desde seu início pela escola e sua comunidade, pois seu objetivo é partir da realidade concreta da escola e suas reais necessidades.

Com referência ao processo de participação na escola, o entrevistado G1 afirmou que a APP e o Conselho Deliberativo são bem participativos. O Grêmio Estudantil também é bastante atuante. G2 relatou que sempre que é necessária a presença do Conselho e APP não se tem problemas, mas ao falar dos demais pais afirmou que eles geralmente não são muito participativos. A gestora também relatou que na primeira reunião, quando da entrega de boletins, eles costumam vir à escola, mas não chega a $100 \%$ ou só quando é encaminhado bilhete solicitando sua participação em caráter de urgência.

[...] hoje eu percebo que eles estão um pouco mais presentes, mas não é o ideal para o acompanhamento das atividades escolares dos filhos. Cerca de $70 \%$ não acompanham o rendimento escolar de seus filhos. Nos eventos organizados pela escola, como: festa da família, festa junina e o natal, os pais participam mais. No entanto, aqueles que mais precisam são os que menos aparecem. (GESTORA 2, 2019).

Saberes Pedagógicos, Criciúma, v. 4, n², maio/agosto 2020.- Curso de Pedagogia- UNESC 
Segundo G3, a participação já foi melhor, os pais não têm mais tempo de estar na escola. Quando se trata da parte financeira, a APP e o Conselho não se negam a estar na escola quando necessário. Destacou que quando necessita de alguma assinatura ou mostrar algum documento precisa se deslocar até a casa dos pais ou responsáveis.

[...] eu digo sempre para os meus alunos que gostaria de ter os pais na escola. Mas, graças a Deus que é uma comunidade pequena e eu os conheço, pois poucos participam e se envolvem com as questões da escola. Não me nego de ir em suas casas quando o caso relativo ao filho necessita, chego a ir até no final de semana. (GESTORA 3, 2019).

De acordo com Lopes (s/d, p. 4):

É importante que os pais ou responsáveis pelas crianças demonstrem interesse em tudo no que diz respeito à escola do filho, para que ele perceba que estudar é algo prazeroso e indispensável para a vida. A participação dos pais na educação formal dos filhos deve se proceder da maneira constante e consciente, integrando-se ao processo educacional, participando ativamente das atividades da escola. Essa interação só tem a enriquecer e facilitar o desempenho escolar da criança.

Sendo assim, é relevante que a família seja uma presença ativa na escola, seja na participação em eventos ou nos processos de acompanhamento do rendimento escolar dos filhos. Participar conjuntamente com a escola favorece, sobremaneira, a melhoria do processo ensino-aprendizagem.

Com os relatos dos três diretores percebeu-se que o processo de participação é mais efetivo por meio dos canais de participação e ocorre mais durante os eventos e atividades culturais. No entanto, essa participação ainda é muito incipiente no acompanhamento do processo de aprendizagem dos filhos.

Quando indagada sobre o papel específico do Conselho Escolar na gestão da escola, o entrevistado G1 destacou: “[...] Conselho Escolar aqui na gestão participam esporadicamente, embora a escola insista para que todos participem nos eventos da escola e procuram distribuir as funções.” G2 afirmou que “[...] o Conselho Escolar possui um papel deliberativo e de aconselhamento, além de propor ações. No entanto, há pouco interesse dos pais nessa participação, por mais que a escola mostre sua importância e a força que possui." 
G3 ressaltou que “[...] sempre que há a necessidade da presença do conselho na escola os membros participam, mas só em situações especiais."

Assim, percebe-se que nas escolas pesquisadas o Conselho Escolar não atua de acordo com suas atribuições, tornando-se um desafio para a gestão escolar conquistar e se mobilizar para a ampliação dessa participação, pois somente dessa maneira haverá transparência, legitimidade e corresponsabilidade na tomada de decisões e a consequente melhora dos processos democráticos da escola em direção a uma educação cidadã.

\section{CONCLUSÃO}

Este trabalho investigativo está em correspondência com o problema de pesquisa e constituiu-se como estrutura mobilizadora para atingir os objetivos almejados. A finalidade da pesquisa foi analisar a influência da participação da comunidade educativa na construção da gestão democrática. A análise dos dados, no tocante à formação acadêmica e experiência profissional dos gestores, indica que todas possuem uma graduação na área da educação e cursos de aperfeiçoamento na gestão escolar, demonstrando estarem habilitadas para o exercício da atividade gestora.

Com relação ao papel do gestor escolar na construção da gestão democrática, percebeu-se que há o entendimento acerca do gestor como agente mobilizador da comunidade educativa nos processos de participação. Ademais, reconhecem a importância dos órgãos colegiados nas ações da escola como forma de oportunizar discussões coletivas, o engajamento e articulação entre os atores que compõem a comunidade educativa.

Outro ponto digno de pauta tratou sobre o processo de autonomia administrativa, pedagógica e financeira na escola, demonstrando evidências sobre a importância de trabalhar em conjunto com a comunidade educativa, tomar decisões coletivas e a liberdade para gerir seus recursos financeiros de acordo com as necessidades. No processo de gestão democrática, outro aspecto que precisa ser destacado trata da escolha do diretor da escola, quando se constatou que os gestores foram eleitos pelo voto direto de toda a comunidade e possuem um 
plano de gestão aprovado, dando cumprimento aos dispositivos legais e normativos que fundamentam esse processo.

A elaboração do Projeto Político Pedagógico nas escolas pesquisadas não atende aos referenciais que defendem a elaboração do PPP a partir da análise da realidade concreta da escola e com a participação de toda comunidade educativa, pois segue um roteiro prédeterminado pelo órgão central.

Tal fato fica evidenciado quando se verificou que a presença dos pais na escola ocorre por meio dos canais de participação durante as atividades extracurriculares, pois esse envolvimento ainda é incipiente no acompanhamento do processo de aprendizagem dos filhos.

Por fim, quando indagadas sobre o papel específico do Conselho Escolar na gestão da escola, percebeu-se que o Conselho Escolar não atua de acordo com suas atribuições, tornando-se um desafio para a gestão escolar incentivar e mobilizar para a ampliação dessa participação.

Diante dos aspectos acima citados, concluiu-se que embora haja o reconhecimento da influência da comunidade educativa na construção da gestão democrática, há necessidade de buscar outras formas de ampliar e melhorar o processo de participação da comunidade educativa na escola, principalmente as relacionadas à aprendizagem dos estudantes.

Assim, entende que a gestão democrático-participativa deve ser resultado de projetos coletivos, intencionais e colaborativos, de modo a ajudar na construção de uma educação cidadã.

\section{REFERÊNCIAS}

ANTUNES, Rosmeiri Trombini. CARVALHO, Elma Júlia Gonçalves de. O gestor escolar. In: CARVALHO, Elma Júlia Gonçalves de. [et al] (orgs) Gestão escolar. Maringá, PR. Secretaria de Estado da Educação do Paraná: Universidade Estadual de Maringá, 2008. Disponível em:

http://www.gestaoescolar.diaadia.pr.gov.br/arquivos/File/producoes_pde/md_elaine_sinhorini arneiro.pdf

Acesso em: 22. Ago 2019. 


\section{SABERES PEDAGÓGICOS}

Revista do Curso de Graduaçāo de Pedagogia - Unesc

ISSN 2526-4559

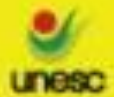

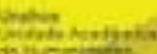

BRASIL. Ministério da educação. LEI No 9.394 de 20 de dezembro de 1996. Disponível em http://portal.mec.gov.br/seesp/arquivos/pdf/lei9394_ldbn1.pdf . Acesso em 27. Ago 2019.

FERREIRA, J. R. A. A.; SOUZA, A. Gestão escolar: desafios e possibilidades. Curitiba. 2009. p. 56.

GALINA, Irene de Fátima. CARBELLO, Sandra Regina Cassol. Gestão democrática e instâncias colegiadas. Antunes, Rosmeiri Trombini. CARVALHO, Elma Júlia Gonçalves de. O gestor escolar. In: CARVALHO, Elma Júlia Gonçalves de. [et al] (orgs) Gestão escolar. Maringá, PR. Secretaria de Estado da Educação do Paraná: Universidade Estadual de Maringá, 2008. Disponível em:

http://www.gestaoescolar.diaadia.pr.gov.br/arquivos/File/producoes_pde/md_elaine_sinhorini arneiro.pdf

Acesso em: 22. Ago 2019.

GIL, Antonio Carlos. Como elaborar projetos de pesquisa. 4. ed.-São Paulo: Atlas, 2002.

LIBÂNEO, José Carlos. Educação escolar: políticas, estrutura e organização. 2 ed. São Paulo: Cortez, 2005.

LIBÂNEO, José Carlos. Organização e gestão da escola: teoria e prática. 5. ed. Goiânia: MFLivros, 2008.

LIBÂNEO, José Carlos. Organização e gestão da escola: Teoria e prática. 6. ed. São Paulo: Heccus, 2015. p. 304.

LOPES, R.C. A. A importância da participação dos pais na vida escolar dos filhos. s/d.

PARO, Vitor Henrique. Gestão democrática da escola pública. 3. ed. São Paulo: Ática, 2001. p. 119.

PINHEIRO, José Maurício. Da iniciação científica ao TCC: uma abordagem para os cursos de tecnologia. Rio de Janeiro: Ciência Moderna, 2010. xv, p.161.

SANTA CATARINA. Secretaria de estado de educação. Decreto $\mathbf{n}^{\mathbf{0}} \mathbf{2 4 3}$, de $\mathbf{1}^{\circ}$ de julho de 2015. Disponível em: http://www.sed.sc.gov.br/legislacoes-estadual-e-federal/plano-degestao-escolar-409/processo-2015-568/2678-decreto-sc-n-243-de-1-de-julho-de-20154583/file Acesso em: 18. Set. 2019. 
SANTA CATARINA. Secretaria de estado de educação. Diretrizes para o conselho deliberativo escolar. Florianópolis, mar/2018. Disponível em:

file://C:/Users/acer/AppData/Local/Temp/Diretrizes\%20para\%20o\%20Conselho\%20Deliber ativo\%20Escolar\%20-\%20CDE.pdf Acesso em: 18. Set. 2019.

TRIVIÑOS, A.N.S. Introdução à pesquisa de ciências sociais: a pesquisa qualitativa em educação. São Paulo: Atlas, 1987.

VEIGA, Ilma Passos Alecanstro. Projeto político-pedagógico da escola: uma construção coletiva. 14. Ed. Papirus, 2002. p. 10.

VEIGA, Ilma Passos Alecanstro (Org.). Projeto político-pedagógico da escola: Uma construção possível. 29. ed. Campinas, São Paulo: Papirus, 2013. p. 192. 